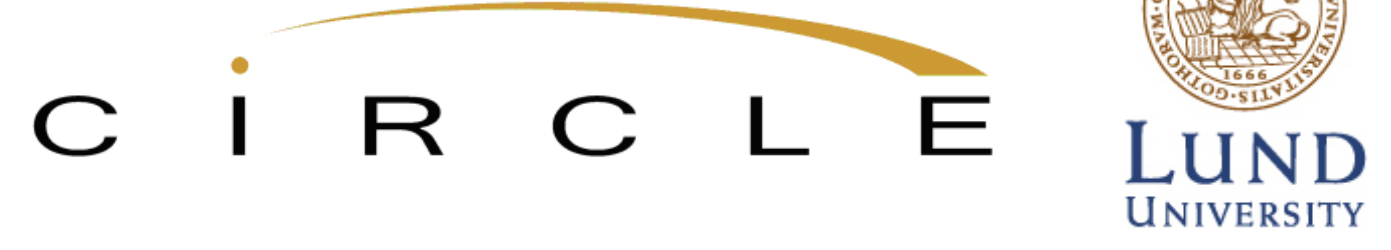

Paper no. 2009/10

\title{
Dynamics of a Technological Innovator Network and its impact on technological performance
}

Ju Liu(liuju@uestc.edu.cn) University of Electronic Science and Technology of China, Chengdu, China

Cristina Chaminade (cristina.chaminade@circle.lu.se) CIRCLE, Lund University

This is a pre-print version of an article that has been accepted for publication in Innovation Management Practice \& Policy. (c) All rights are reserved.

Centre for Innovation, Research and Competence in the Learning Economy (CIRCLE) Lund University

P.O. Box 117, Sölvegatan 16, S-221 00 Lund, SWEDEN

http://www.circle.lu.se/publications

ISSN 1654-3149 
WP 2009/10

Dynamics of a Technological Innovator Network and its impact on technological performance

Ju Liu, Cristina Chaminade

\begin{abstract}
This paper examines the dynamics of a technological innovator network (TIN) of a stateowned textile company in the underdeveloped southwest China. It addresses two research questions: how the structure of the TIN evolved in the past ten years and what impact it had on the technological performance of the firm. The case study reveals that the general structure of the TIN and the positioning of the actors influence not only the amount of technological innovations but also the predominant type (product versus process innovations). TIN that are adequate for process innovation may not be as efficient for product innovation.
\end{abstract}

Keywords: Technological innovator network; Technological innovation performance; Product and process innovation, Network structure, Network Dynamics, China

Disclaimer: All the opinions expressed in this paper are the responsibility of the individual author or authors and do not necessarily represent the views of other CIRCLE researchers. 


\title{
Dynamics of a Technological Innovator Network and its impact on technological performance
}

\author{
Ju LIU \\ School of Economics and Management \\ University of Electronic Science and Technology of China, Chengdu, China. \\ Cristina CHAMINADE \\ CIRCLE, Lund University, Sweden
}

\begin{abstract}
This paper examines the dynamics of a technological innovator network (TIN) of a state-owned textile company in the underdeveloped southwest China. It addresses two research questions: how the structure of the TIN evolved in the past ten years and what impact it had on the technological performance of the firm. The case study reveals that the general structure of the TIN and the positioning of the actors influence not only the amount of technological innovations but also the predominant type (product versus process innovations). TIN that are adequate for process innovation may not be as efficient for product innovation.
\end{abstract}

Keywords: Technological innovator network; Technological innovation performance; Product and process innovation, Network structure, Network Dynamics, China.

\section{Introduction}

It is now generally accepted that innovation is the result of an interactive process. Innovation is not an isolated process of individuals or firms but is the outcome of the interaction between firms, customers, suppliers, competitors and various other private and public organisations in a system (Lundvall, 1988, 1992). Through a complex web of interactions, individuals and organisations exchange the knowledge needed for the development of new products or processes or the improvement of existing ones. Understanding the drivers of innovation requires an in-depth analysis of the social relationships and organisational structures supporting the exchange of knowledge and information across the different actors in an innovation system (Lundvall, 2004).

Consequently scholars in innovation studies have largely analyzed the role of networks in the generation of ideas and its transformation into new products or processes (Powel and Grodal, 2005). Broadly speaking, an innovator network can be defined as web of individuals or organisations whose interaction supports the 
emergence and development of innovations. While some authors have been mainly concerned with the geographical location of innovator networks or its stickiness (Beccatini, 1990, Camagni, 1991, Cooke, 1996, 1998, Marshall, 1930, Piori and Sabel, 1984, Storper, 1997, Asheim and Gertler, 2005), others have largely studied how the intrinsic characteristics of the network in terms of structure (Das and Teng, 2002), governance (Pietrobelli and Rabellotti, forthcoming, Gereffi, 2005, Sturgeon and Van Biesebroeck, 2008), cognitive distance between the participants of the network (Gilsing et al, 2008) or the strength of the ties (Granovetter, 1973) affect the transfer of knowledge and consequently the emergence or development of innovations (Nooteboom, 2004) . While this line of studies has been extremely helpful in understanding how networks might support the emergence and development of innovation, they still are rather limited.

Most scholars have focused on the role of inter-organisational networks shaping innovation (DeBresson and Arnesse, 2001, Freeman, 1991, Hagerdoorn, 1990, 1993, Nooteboom, 2004, Powell et al, 1996, Soh and Roberts, 2003) and innovation systems (Giuliani and Bell, 2005, Kastelle et al, 2009). There is yet a limited amount of empirical studies on the role of intra-firm networks on innovation and organisational learning (Dantas, 2006, Jensen et al, 2007) and even less of the interplay between intra and extra-organisational networks shaping innovation.

Furthermore, most of the studies conducted hitherto are based on qualitative methods of analysis. When quantitative analysis has been performed, authors have had mainly focused on formal networks as the independent variable and patents as the dependent variable neglecting other forms of networks as well as other measures of innovative output like new products, services, organisations, etc. (Powell and Grodal, 2005). Hitherto most of the studies on intra-firm networks are at the individual level in which individuals are taken as nodes of the network. Networks of groups and organisations are not very common. The reason is that some researchers doubt if it is possible or applicable to use social network analysis ( SNA ) to other type of nodes than individuals.

The lack of empirical studies is particularly dramatic traditional industries ${ }^{1}$. The studies often examine high-tech industries where technological collaboration is paramount for the success of innovation projects.

This paper attempts to analyze the dynamics of a technological innovator network (TIN) in the past ten years of a state-owned company named Grace Corporation. Grace is an innovative company in a traditional industry - textileslocated in the relatively underdeveloped Southwest China. The paper opens the black box of the company by taking the different functional departments as research units. It breaks the organisational boundary by having the outside organisations involved

\footnotetext{
1 Take ABI/INFORM database as an example, we found 1528 papers by the key words of innovation, network, and high-tech, but only 13 papers by innovation, low-tech or medium-tech or traditional industry. It is also deficient in research on developing countries, in particular the underdeveloped area of these countries.
} 
into the network. We explore how the structure of the intra-firm and extra-firm TIN evolved in the ten years of technological innovation and how it impacted on both process and product innovation. For doing so, we use social network analysis to map and measure the relationships between different departments and organisations inside and outside the company. The social context and economic environment of relatively underdeveloped Southwest China are considered as important background and influencing factors that shaped the pattern of technological innovation in this case. Case study is used as our main research method, as we believe that this can help us to have a clear picture of the dynamics of TIN inside a firm and get deeper insights into how TIN impacts technological innovation.

The reminder of the article is structured as follows. In the next section we review the literature on innovator networks and technological innovation paying particular attention to the links between the two. In section three and four we describe the research methodology and the analytical framework that we will use in our analysis. The company that we analyse in our study -Grace Corporation- is presented in section five and the results of the analysis are depicted in section six. Finally, we discuss the theoretical and empirical implications of our analysis in a concluding section.

\section{Theoretical Background}

\subsection{Technological innovation as a networking process}

Among innovation scholars, it is generally accepted that firms and other organisations do not innovate in isolation but in continuous interaction with other organisations, conforming a system of innovation. Innovator networks shape the structure and dynamics of a system of innovation and thus its performance and vice-versa; the institutional frameworks and the socio-economic structure in which the actors are embedded also determine the form and functioning of the networks.

Technological innovator networks are complex structures embracing horizontal and vertical linkages and embracing all activities supporting the emergence and development of new products or processes. Among these supporting activities, one can include financial services, technology suppliers and more general knowledge suppliers, etc. In the social network analysis literature (Scott, 2002) networks are defined as a set of nodes connected by a set of ties. Nodes are the actors or players of the network. They are considered as interdependent rather than independent autonomous units.

One could argue that there are two main lines of research concerned with innovator networks. Those focusing on the ecology of the network, that is, how external factors such as formal and informal institutions or the embeddedness of the innovator network in a specific location influence the dynamics of the network. And those analysing the internal characteristics of the network in terms of composition or structure, governance, properties of the ties, capabilities of the actors involved in the network, etc. 
According to the first line of research, clearly dominated by economic geographers, proximity with other members of the network facilitates the exchange of codified but more importantly non-codified or tacit knowledge (Beccatini, 1990, Camagni, 1991, Cooke, 1996, 1998, Marshall, 1930, Piori and Sabel, 1984, Storper, 1997, Asheim and Gertler, 2005). Tacit knowledge is more difficult to transfer than codified knowledge. Accessing tacit knowledge often requires a close interaction with the source of that knowledge. This sticky character of knowledge explains the strong geographical embeddedness of certain networks forming clusters and the success of certain regions such as Silicon Valley (Saxenian, 1994) or the so called Third Italy (Beccatini, 1990). The degree of trust among the participants in the network as well as a shared culture facilitate the exchange of knowledge and point to the importance of institutions in the dynamics of the networks (Lundvall, 2007, Johnson, 1992) while the existence of different cultural backgrounds might hinder the transfer of knowledge among the participants of the network (D’Costa, 2003).

Following the second line of research, three elements are usually taken into account when analysing the intrinsic characteristics of the networks: the general structure of the network, the positioning of the individual actors in the network, and the strength of ties between the actors. What are they and what might be the expected impact on technological innovation is discussed next.

\section{Structure of the network}

The size and composition of the network, the density of the network and its centrality are important aspects to consider when discussing the potential impact of networks on technological innovation.

Although most authors equal networks to inter-organisational networks it is possible to distinguish between inter-firm networks (DeBresson and Amesse, 1991), inter-organisational networks (Freeman, 1991) and even intra-firm networks supporting innovation (Tsai, 2001, Lam, 2005, Nonaka and Takeuchi, 1995). In inter-firm networks all nodes are firms and all ties are between firms. Studies on user-producer networks (Lundvall, 1992), inter-industrial networks and clusters (Malmberg and Power 2005, Porter, 1998) are usually inter-firm networks. Inter-organisational networks involve other types of organisations, such as universities, research centers, financial institutions or the government. The innovation systems literature (Lundvall, 1992, Asheim and Gertler, 2005, Malerba, 2005) as well as the most recent cluster literature (Porter, 1998) implicitly use this definition of a network. Finally the concept of intra-firm network has been mostly used in organisational studies to refer to the linkages established between different departments of the firm (Lam, 2005). With very few exceptions (Lundvall, 2007) these two approaches (inter vs. intra firm networks) have mostly evolved in parallel and with very few interactions ${ }^{2}$.

${ }^{2}$ Lundvall (2007) argued that the impact of innovation on economic performance will typically depend upon changes in "people", "orgware" which refers to how people relate to each other within 
The density of the network is usually measured in terms of the number of direct ties between the participants of the network (Scott, 2000). The density of the network has important implications in terms of the access to competences and the governance of the networks and thus on innovation. Sabatier and Jenkins-Smith (1993) argued that dense structures tend to reinforce inertia and can be hostile to innovation, while McCarthy (2008) had opposite conclusion that a dense network helped spread institutional norms of behavior and it also facilitated the transfer of information which is important to innovation. The latter studied the process of network evolution and transformation in health insurance in Ireland and found that the network was characterized by high centrality, high density and weak ties, and cost efficiency was a key outcome. The positive relation between density of network and learning is also justified by the research by Tsai (2006) on the impact of website structure on customer knowledge flow and innovation in internet marketing in Taiwan and the extensive literature on clusters (Saxenian, 1994, Piore and Sabel, 1984). Carlsson and Sandström (2008) conducted a comparative case study of four networks within the higher education policy sector and proposed that an efficient and innovative policy network consists of a heterogeneous set of actors that are centrally and densely integrated.

The degree of centrality measures the extent to which a network is centralized. It has important implications in terms of learning and innovation as it influences, for example, to what extent other actors can participate in the network, the bargaining power of the different actors or the control of information (Nooteboom, 2004). Pietrobelli and Rabellotti (forthcoming) show that very centralized forms of networks with hierarchical or captive patterns of interaction tend to hinder the transfer of knowledge and thus interactive learning and innovation is less likely to occur. In more decentralized networks where there is no clear dominant actor that controls important direct ties, other actors can access information more fluidly. An increase in the degree of centrality might imply a risk if the central actor restricts the access of information to other actors but it might also facilitate the coordination of different actors which might be required in complex innovation processes. About the relation between network centrality and innovation, Herminia (1993) argued that network centrality is the strongest determinant of individual involvement in innovation efforts for administrative innovation but not for technological innovation. Ebadi and Utterback (2000) studied 117 Sea Grant research projects and found that on the one hand, on individual level frequency of communication affects technological innovation and so does centrality and diversity; on the other hand, on the organisational level, network cohesiveness, centrality, and diversity of communications all were positively related to technological innovation. In sum, as with most of the variables discussed in this section, the impact of centrality on

organisational borders, and "socware" which refers to how people relate to each other across organisational borders. The "orgware" and "socware" are interpreted as the structural attribution of intra-firm network and inter-organisational network in this paper. 
innovation is not clear.

\section{Positioning of individual actors}

All sociologists would agree that power is a fundamental property of social structures and is inherently relational. Hanneman and Riddle (2005) argued that power in social networks may be viewed either as a macro property which describes the entire population or as a micro property which describes relations between actors. Burt (1992), Wasserman and Faust (1995) also defined two approaches in network analysis with one approach focusing on the whole of the network itself and another on characteristics of particular actors in a network. As with other key sociological concepts, the macro and micro are closely connected in social network thinking.

We may expect that the positioning of individual actors and how they are connected to other actors of the network has also important implications in terms of technological innovation. A central or bridging positioning in the network or a close link to an actor that has multiple connections ensures the access to critical resources (Scott, 2000, Nooteboom, 2004). On the contrary, a peripheral position in the network and the need to go through many nodes to access the relevant information might severely hamper the flow of knowledge within the network and thus innovation.

\section{Strength of ties}

The positioning of individual actors is also related to the strength of the ties that the actor has with the other actors within the network. There is a large amount of literature on the advantages of weak (not intense) vs strong (intense) ties in networks (Granovetter, 1973). But (again) it is not conclusive when it comes to the impact of the intensity of the networks on innovation; On the positive side, weak tie networks may provide access to novel and non-redundant information and introduce flexibility in the network while strong ties may facilitate the exchange of complex information. On the negative side, strong ties may end up in lock-in situations and lack of renewal of ideas and knowledge (D'Costa, 2002, Narula, 2002).

\subsection{Technological innovation including product and process innovation}

Technological innovation in this paper refers to product innovation which are new or better material goods as well as new intangible services and process innovation which are new ways of producing goods and services (Edquist, 2005). Innovation is generally considered to be the development and introduction of new products or new processes or new forms of organisation in the firm. As argued by Fagerberg (2005), despite one of the founders of innovation studies -Schumpeter- considered at least five different types of innovation: new products, new methods of production, new supply sources, access to new markets and new forms of organisation, innovation scholars in general and economists in particular have mainly focused on just the two first ones: product and process innovation. This will be also the approach followed in this paper. 
One of the most used definitions of innovations is the Oslo Manual one (OECD, 2002). The Oslo Manual distinguishes between technological and non-technological innovations and between products and processes. According to the Oslo Manual (OECD, 2002), technological innovations "comprise implemented technologically new products and processes and significant technological improvements in products and processes" (OECD, 2002: 31).

Product innovations comprise both goods and services and they refer to technologically new products and technologically improved products. Technologically new products are products "whose technological characteristics or intended uses differ significantly from those of previously produced products. Such innovations can involve radically new technologies, can be based on combining existing technologies in new uses, or can be derived from the use of new knowledge" (op.cit: 32). On the other hand, technologically improved products are products "whose performance has been significantly enhanced or upgraded. A simple product may be improved (in terms of better performance or lower cost) through use of higher-performance components or materials, or a complex product which consists of a number of integrated technical sub-systems may be improved by partial changes to one of the sub-systems" (op.cit: 32).

Process innovation, as defined by the Oslo Manual, is "the adoption of technologically new or significantly improved production methods, including methods of product delivery. These methods may involve changes in equipment, or production organisation, or a combination of these changes, and may be derived from the use of new knowledge. The methods may be intended to produce or deliver technologically new or improved products, which cannot be produced or delivered using conventional production methods, or essentially to increase the production or delivery efficiency of existing products" (op. cit: 32 ).

\section{Research Methodology}

When studying the complicated dynamics of technological innovator network (TIN) there is no single method which is competent. Therefore, phenomenology methodology and case study method and social network analysis were adopted in this paper.

\subsection{Case study}

Case study method is used to understand the major issues surrounding the technological innovation in Grace. Different sources of evidence are utilized, including questionnaire, interviews, direct observation, archives and statistics. In the data collection phase, we used one semi-structured questionnaire to collect the relational data of the TIN of Grace. Overall, six visits were made during the period of December 2004 to January 2008 and conducted 25 interviews. The interviewees included the president and chairman of the board, the vice-general manager, the directors of the middle-level management team from seven different sections -- the 
Science and Technology Administration Department, the Domestic Marketing Department, the International Marketing Department, the Strategic Planning Department, the intellectual property right (IPR) Office, the HR Department, and the Real Estate Company and individual engineers and workers. Typically each interview lasted for about 1 to 2 hours. The interview phase lasted for about 8 non-consecutive weeks ${ }^{3}$. An agreement was reached with Grace over business secrecy. Informal discussions with the members of the organisation provided us with a better understanding of the important themes underlying the firm's practice of organisational learning and technological innovation. In the data clarification and complementation phase, we contacted Grace's managers via email correspondence and telephone discussions for further information and data, and to clarify unclear points from the previous interviews.

\subsection{Social network analysis}

Social network analysis (SNA) was adopted as the analytical tool in this research. The social network perspective encompasses theories, models, and applications that are expressed in terms of relational concepts or processes (Wasserman and K. Faust, 1994). Social network analysis focuses on uncovering the patterning of people's interaction. It is based on an assumption of the importance of relationships among interacting units and on the intuitive notion that these patterns are important features of the lives of the individuals who display them.

The software of NetDraw and Ucinet were used to map the TIN of Grace and detect the properties of the network in order to understand the pattern and dynamics of it.

\section{Analytical Framework}

\subsection{Definition of the technological innovation network}

In this paper we define a technological innovator network (TIN) as a combination of intra-firm and inter-organisational networks.

In the intra-firm network of this paper, instead of commonly taking individual as the node, we identify the nodes as groups of people who serve in different functional department such as marketing, financial, $R \& D$, and human resources (HR) within the firm. Some researchers question if there is a need to talk about network of groups which are already made of individuals involved in social networks. We argue that SNA on networks of groups and organisations is both applicable and necessary. On the one hand, SNA is based on an assumption of the importance of relationships among interacting units or nodes. If relations between individuals are defined by linkages among them (Scott, 2000), it is also applicable to define the relations between groups, or more general, organisations in the same way. However, SNA on

\footnotetext{
${ }^{3}$ All the interviews were well recorded but not taped since the informants were reluctant to share their views in front of a tape recorder.
} 
network of groups/organisations is different from and non-substitutable by SNA on networks of individuals. Organisational behaviour can be analyzed at three different levels, namely individual, group, and organisation (Robins, 2002). A group is a combination of individuals but the behaviour of a group is not a simple addition of the behaviour of individuals thanks to the synergy and antagonism between individuals. Therefore, distinguishing network of individuals and network of groups/organisations is necessary. Furthermore SNA on networks of individual, which is at the very micro level, is more suitable for HR workers rather than for general strategy makers who need information of middle scale level.

In the inter-organisational network of this research, the nodes are formal structures that are consciously created and have an explicit purpose (Edquist and Johnson 1997). They are organisational actors such as educational and scientific research institutes, non-governmental investment institutions, customers, suppliers competitors, and so on.

The focus on the interplay between intra and extra-firm networks makes the picture of firm's technological innovator network complete and clearer than just focus on either of these two networks. We can therefore deeply understand how firm's functional strategy, which concerns the managerial game plan for running a major functional activity or process such as $R \& D$, production, etc. within a firm, copes with firm's business strategy, which concerns the actions and the approaches crafted by management such as building up collaborative partnerships and strategic alliances to produce successful performance in the firm's business.

For the analysis we will consider both formal and informal ties. Network dynamics in this paper refers to the evolving or changing structure of the network, such as breaking or making of ties. We attempt to take snapshots for the TIN during its evolutionary process in the past ten years ${ }^{4}$.

\subsection{Parameters to analyse the technological innovation network}

Following the discussion in the previous section, we use two main groups of parameters in this paper: the first is network properties to describe the TIN structure as a whole and a second one is node properties to identify and understand the position which reflects the opportunities and constraints of a specific actor in the network. The network properties referring to the structure of the network include composition of the network, density, centralisation, efficiency, and diversity. The node properties regarding the positioning of actors in the network comprise node centrality, including Freeman (1979)'s degree and Bonacich (1972)'s power, closeness, and betweenness. These measures have come to dominate empirical usage to identify the most important actors within the network (Borgatti, 2005). Each measure has various relative advantages and disadvantages concerning its use.

\footnotetext{
${ }^{4}$ In doing so, we consciously ignore the dynamics on the network due to the change of the actors themselves.
} 
We define these measures as follows.

\section{Structure of the network}

Composition of the network: In this paper, we identify eight internal actors, which are different functional departments and groups inside the company, and ten external actors, which are different organisations outside the company (see Table1). To examine the connections between inside actors we asked the question: "Do the different functional departments and groups contact each other when doing technological innovation activities?"

Table1. Abbreviation of actors

\begin{tabular}{llll}
\hline & Inside Actors & & Outside Actors \\
\hline PRD & Production Department & UNI & Universities \\
\hline FIN & Financial Department & RI & Research Institutes \\
\hline HR & Human Resource & SPL & Suppliers \\
\hline RD & R\&D Department & CST & Customers \\
\hline \multirow{2}{*}{ ST } & Science \&Technology & CPT & Competitors \\
\cline { 3 - 4 } & Administration Department & GOV & Government \\
\hline MKT & Marketing Department & INV & Private Investors \\
\hline PCH & Purchasing Department & LAW & Legal Services Agencies \\
\hline LOG & Logistic Department & CSL & Consulting Companies \\
\hline & & IA & Industrial Associations \\
\hline
\end{tabular}

Density is a measure of the connectedness between nodes in a network (Scott, 2000). It is expressed as a proportion of the actual number of ties to the maximum possible number of ties in a network. Scott (2000) pointed out that density is the most widely used and the most possibly abused concept as it is sensitive to the size of network. It cannot be used for comparisons across networks that vary significantly in size. As what we analyze is the same network with not significant change in size, the density of the TIN of Grace in different periods of time is comparable.

Centralisation of the network expresses the degree of inequality or variance in the network as a percentage of that of a perfect star network of the same size. It measures to what extent the network as a whole is centralized.

Additionally, we measure the Efficiency of the network as the extent of difficulty for a node to get access instantly to a large number of different nodes through a relatively small number of ties. Its proxy is the average distance of the network.

\section{Positioning of actors}

Degree centrality reflects how a node is connected in the local environment. It is expressed by the number of direct ties with other nodes. High degree means more ties which provide the actor with alternative ways to satisfy needs, and more chances to be the third-parties and deal makers in exchanges among others. Consequently actors with high degree of centrality are in an advantaged position. To measure the degree centrality of the network actors, we use both Freeman's degree and Bonacich power. 
Freeman's degree measures the degree of variance in a network as a percentage of that of a perfect star network of the same size. Bonacich power can be considered as an advanced version of Freeman's as it captures not only the direct ties to other nodes but also the ties that those other nodes have (Hanneman and Riddle, 2005).

Closeness reflects to what extent a node is the center of the network. It is expressed by the sum of the distances from a particular node to the other nodes in the network. It emphasizes the distance of an actor to all others in the network by focusing on the distance from each actor to all others.

Betweenness reflects to what extent a node is standing in between of the others. Together with closeness, betweenness measures an actor's capacity to control communication in a network, which depends on its relations to all members of a network and not necessarily on the number of links to immediate neighbors.

\section{Strength of tires}

To measure the strength of the connections to the company's technological innovation, we asked the respondent to score the importance of connection which is represented by the five-level Likert item. We also did the same examination and measurement regarding the connections between the inside actors and outside actors, as well as the connections among the outside actors. The responses allow us to conduct the core-periphery analysis which will be presented in the next section.

\subsection{Technological innovation performance}

In this study, technological innovation includes product innovation and process innovation. The percentage of the sale of new products to the total sale is used to measure the product innovation performance. The number of successful process innovation projects is used to measure the process innovation performance.

The new products refers to the products which were developed and produced by new technological elements and new design, or those which have obvious improvement in structure, material, and process compared to the existing ones, or in general those which have obvious improved performance or expanded functions. Considering the nature of chemical fiber products, we set a period of three years of expiry for the new products from the year they are first introduced into market.

The successful process innovation projects refer to those whose outcomes have been put into practice in the year.

In order to compare these two different categories of performance and to have a comprehensive measurement of technological innovation performance as a whole we use an efficacy coefficient method to turn the two indicators into comparable indexes. The model of these indexes is as follows:

$$
d_{j}(x)=\left(f_{j}(x)-f_{j \min }\right) /\left(f_{j \max }-f_{j \min }\right) \times 40+60 \in[60,100], \quad j=1,2, \ldots, p
$$




$$
\begin{aligned}
& D=\left(\prod d_{j}(x)\right)^{1 / p} \\
& j=1 \\
& d_{j}(x) \text { - single index, i.e. index of product/process innovation performance } \\
& D \text { - multi objective, i.e. index of technological innovation performance }
\end{aligned}
$$

\section{Case Description}

This paper is based on observations of technological innovation activities in a state-owned textile company named Grace Corporation which is located in Yibin city of Sichuan province in Southwest China. It grew out of a small state-owned chemical fibre factory founded in 1984. Until 1997 it was a small factory on the edge of bankruptcy. 1997 was a milestone in the history of Grace marked by the change of top management and the invention of a revolutionary technology called " $2 \mathrm{~S}$ " which can double the production at very low cost. ${ }^{5}$ Since then Grace experienced a high growth rate, that is, increase at an average annual rate of 35 per cent. Now it is one of the world's largest manufacturers of viscose filament yarn, rayon embroidery thread and hand knitted garments with total assets of 3.9 billion RMB and 12,000 employees. The world market share of its products reached 29 per cent in $2007^{6}$

There are many outstanding occurrences related to technological innovation in this company which break from common trend in China.

First, in this company the annual R\&D investment as a percentage of sales increased from 3 to 9 per cent in the past seven years, a figure far higher than the average level of 0.2 to 0.5 per cent in China's textile companies.

Second, this company benefits significantly and continuously from a technological innovation - "2S". This technological innovation has strongly supported the high growth of this company at an average annual rate of 35 per cent in the past ten years.

Third, they have 114 patents compared with the average of below 8 patents for the import and export enterprises in Sichuan province. ${ }^{7}$

Forth, there is a strong corporate culture supporting innovation. Innovation has the most priority in Grace. The Grace managers are required to pay more attention to innovation than to daily production. Innovation performance is the most important

\footnotetext{
${ }^{5} 2 \mathrm{~S}$ is a process innovation which doubles the production output at very low cost. It breaks with the conventional principle of spinner designing which has existed for more than one hundred years. The typical methods to raise output of spinning machines are to lengthen the spinner or to speed up spinning. These two approaches are either costly or restricted by the technical limits of spinner. But $2 \mathrm{~S}$ does it differently. Traditionally the spinner produces one filament with one spindle. With the $2 \mathrm{~S}$ technology, the spinner can produce two filaments with one spindle at the same time. $2 \mathrm{~S}$ is a radical innovation which is described as an A-bomb in textile industry.

${ }^{6}$ Source: Publicity Department, Yibin Grace Group Co., Ltd.

7 Source: Publicity Department, Yibin Grace Group Co., Ltd. Report of the Soft Science Project of State Intellectual Property Office of People's Republic China "Investigation and Case Study of The Situation of Intellectual Property Rights In Sichuan Import \& Export Enterprises"
} 
criteria for compensation. When it comes to encouraging technological innovation, the most famous notion of the Grace President is "rather incorrectly reward 1,000 people who doesn't deserve than omit one person who deserves". The innovative culture of Grace encouraged people to do their best to innovate in the company and successfully created an internal environment for innovation when the external environment is still conservative.

Fifth, in this company it is difficult to find one single successful joint research program with social knowledge infrastructures such as universities and scientific research institutes in the past ten years. The overwhelming majority of technological innovations are from within the company. It appears that introverted innovator network has successfully supported the prosperous technological innovation activities in Grace. The question, as we will discuss later, is if this is sustainable in the long term.

\section{Case Analysis}

We analyze the dynamics of the TIN of Grace in the past ten years in relation to its technological innovation. The analysis was conducted as follows. First, we divided the history of Grace's technological innovation into three different stages. Second, we took snapshot for each of these stages using a socialgram to give an intuitive image of the TIN of Grace. Third we detected the properties and analyzed the dynamics of the TIN of Grace over these three stages to see how the evolution of the TIN's structure influenced the firm's technological innovation.

\subsection{Three stages of Grace's technological innovation history}

We divided Grace's technological innovation history taking into account the performance of its technological innovation including the performance of product innovation and process innovation and the discussions maintained with Grace managers and president. According to them, the history of Grace's technological innovation can be divided into three stages: 1997-1999, 2000-2004, and 2005 - 2007.

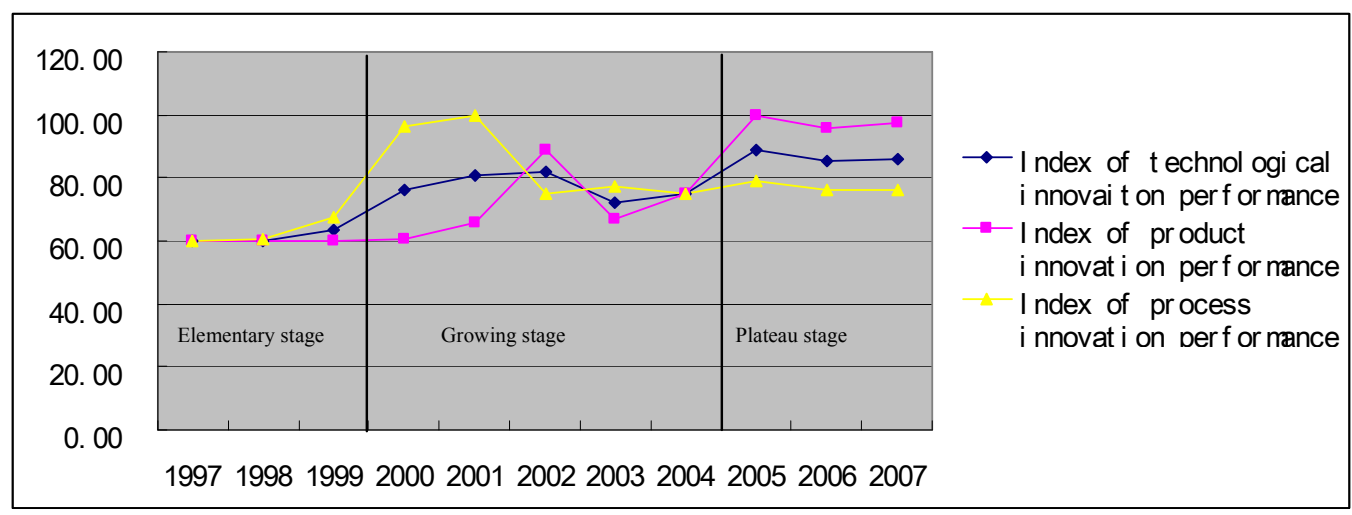

Graph1: Technological innovation performance of Grace from 1997 to 2007 
The first stage running from 1997 to 1999 is considered as the "elementary stage of technological innovation". It is characterized by three historical events. The first is the change of top management. The current Chair and President Feng Tao was assigned by the local government. The second is the invention of the historically important technology " $2 \mathrm{~S}$ ", which is a process innovation which makes it possible to double the production at a very low cost. The third is the massive recruitment of 600 new employees. This directly led to a blood-transfusion -like organisational change. Most of the current mid-level managers are from this group of people. This stage is a turning point changing a old factory in the verge of bankruptcy to an innovative enterprise. But the innovation performance was not high or significant yet.

The second stage from 2000 to 2004 is labelled as the "growing stage of technological innovation". It is also called by Grace the "first spring of technological innovation". The main characteristics of this stage are the invention of a large number of influential and profitable technologies, and the rapid growth fuelled by the prosperous technological innovation. There are two symbolic events: a boom of patenting including the key technology " $2 \mathrm{~S}$ ", the establishment of Science and Technology Administration Department and IPR Office (both of them report directly to the president), and the launching and implementation of a policy which significantly reward the actors and activities of technological innovation. We observed a drop in the percentage of new product sale to total sale during this period. However, this was not because of a slowdown in technological innovation but because of a market reason. In 2003 to 2004 2S technology was illegally imitated by all the main competitors of Grace and its sale of new product was significantly influenced by this infringement.

The third stage from 2005 to 2007 is considered by Grace managers as the "plateau stage of technological innovation" of Grace. In this stage, the performance of product and process innovation further increased in 2005 but then dropped slightly and has more or less stagnated at a stable level in the next two years. According to the interviews, this period is characterised by technological- innovation-fatigue of the employees and a lack of technological talents as a result of their movement from technological positions to managerial positions. To boost its technological innovation Grace initiated the creating-the-second-spring-of-technological-innovation campaign by the end of 2005. But the campaign was not very successful.

The analysis of some indicators of technological performance during this period provides additional information on what has happened in terms of technological innovation in Grace over this 10 period year. As Graph 1 and Table 2 shows, until 2001 Grace excelled in process innovation. The period between 2002 and 2003 is an inflexion period. From 2004 onwards, the technological performance of product innovation excels that of process innovation. This finding is echoed with the strategic transition in Grace. In the first stage, Grace was encouraged by the great success of the famous $2 \mathrm{~S}$ invention which reduced production cost significantly. Many process innovation projects were initiated and succeeded thereafter. But the potential of reducing cost by improving process became more and more limited. After a period of 
prosperousness in process innovation, Grace decided to invest more in product innovation which was believed to be more profitable. The interplay between the technological innovator network (TIN) of Grace and the observed change in the innovation performance of Grace (in terms of the evolution of the indicators as well as the change in the balance of product and process innovation) will be discussed next.

Table 2. Technological performance of Grace over time (1997-2007)

\begin{tabular}{|l|l|l|l|l|l|l|l|l|l|l|l|}
\hline & 1997 & 1998 & 1999 & 2000 & 2001 & 2002 & 2003 & 2004 & 2005 & 2006 & 2007 \\
\hline $\begin{array}{l}\text { Percentage of sale of new } \\
\text { product to total sale }\end{array}$ & 1 & 1 & 1 & 1.4 & 8 & 37.4 & 9.3 & 19.9 & 51 & 45.8 & 47.8 \\
\hline $\begin{array}{l}\text { Number of applied process } \\
\text { innovation projects }\end{array}$ & 3 & 4 & 18 & 74 & 81 & 32 & 37 & 32 & 40 & 35 & 34 \\
\hline $\begin{array}{l}\text { d1- efficacy index for } \\
\text { product innovation }\end{array}$ & 60.00 & 60.00 & 60.00 & 60.32 & 65.60 & 89.12 & 66.64 & 75.12 & 100.0 & 95.84 & 97.44 \\
\hline $\begin{array}{l}\text { d2 - efficacy index for } \\
\text { process innovation }\end{array}$ & 60.00 & 60.51 & 67.69 & 96.41 & 100.0 & 74.87 & 77.44 & 74.87 & 78.97 & 76.41 & 75.90 \\
\hline $\begin{array}{l}\text { D- Efficacy index for } \\
\text { technological innovation }\end{array}$ & 60.00 & 60.26 & 63.73 & 76.26 & 80.99 & 81.69 & 71.84 & 75.00 & 88.87 & 85.58 & 86.00 \\
\hline
\end{tabular}

\subsection{The evolution of the network structure of Grace's TIN and its impact on technological innovation}

We can intuitively see the evolution of the TIN of Grace in three different stages from the snapshots shown in Figures 1,2 and 3 in which the ties that are considered important or very important for innovation are plotted. ${ }^{8}$

\footnotetext{
${ }^{8}$ The shape of the nodes is related with their ID. The square shaped nodes are actors outside of the firm while the round shaped nodes are actors inside of the firm. The size of the nodes is related to their connectedness. The bigger the node is the more connected it is in the TIN. Important and very important connections refer to those weighted 4 or 5 in terms of its importance to technological innovation in the firm according to five-level Likert item.
} 


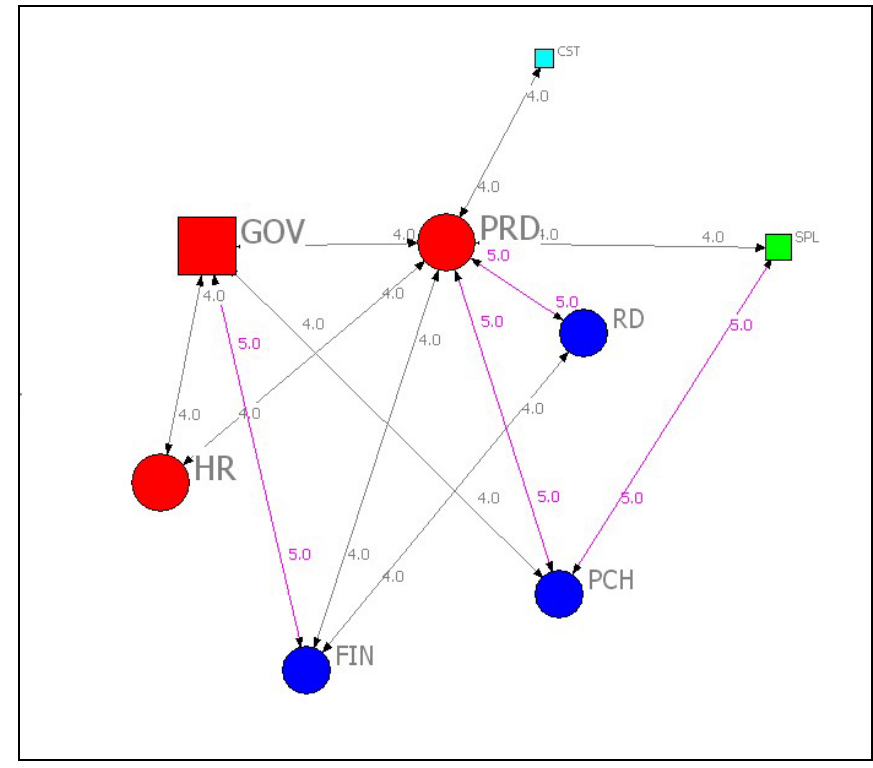

Figure 1. Socialgram with links weighted over 4.0 of TIN in the elementary stage (1997-1999)

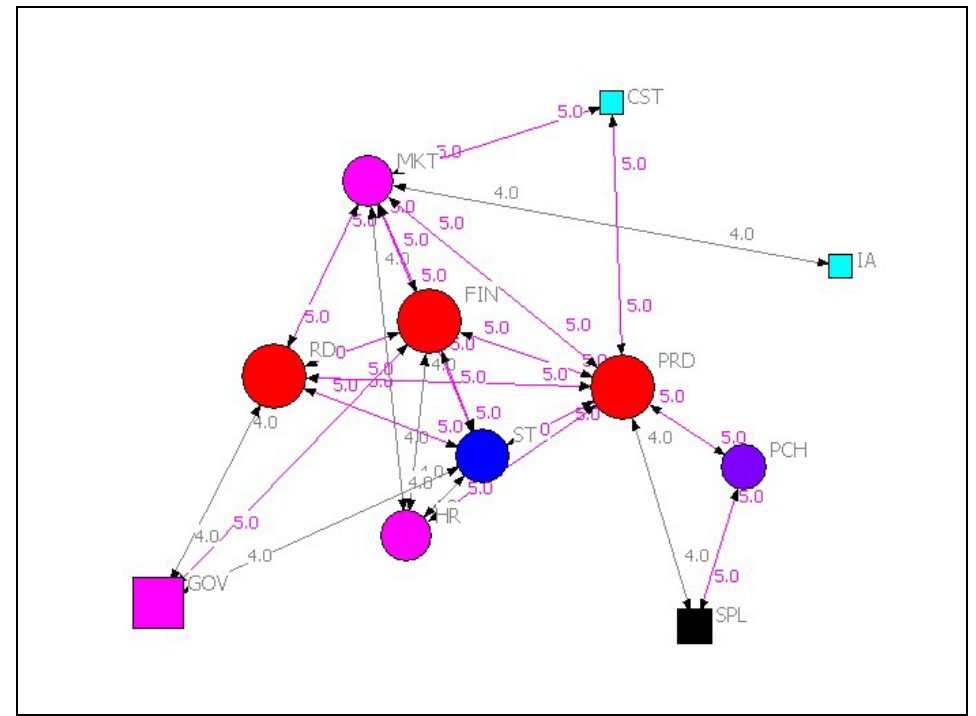

Figure 2. Socialgram with links weighted over 4.0 of TIN in the growing stage (2000-2004) 


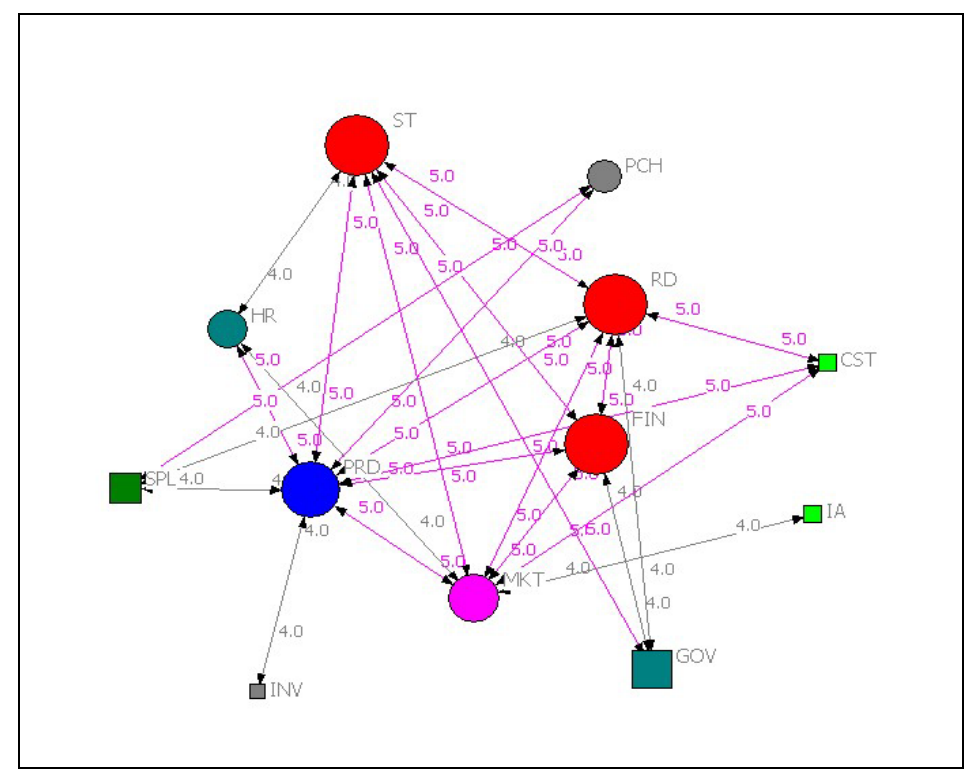

Figure 3. Socialgram with links weighted over 4.0 of TIN in the plateau stage (2005-2007)

The analysis of the sociogram is complemented with indicators of the structure of the TINs over the three stages presented in Table 3 provided some interesting findings. First, the TIN of Grace became more connected and compacted over time. Second, it became larger and more diversified and third, it was inward-looking all the time. The implications that these changes in the structure of the network had on the technological innovation performance of Grace are discussed next.

Table 3: Network properties of the TIN of Grace over the three stages

\begin{tabular}{l|cc|c|cc|}
\cline { 2 - 6 } & \multicolumn{2}{|c|}{ Density } & \multicolumn{2}{c|}{ Centrality } & \multicolumn{2}{c|}{ Efficiency } \\
\cline { 2 - 6 } & Avg. value & Std dev & $\begin{array}{c}\text { Network } \\
\text { centralisation }\end{array}$ & $\begin{array}{l}\text { Average } \\
\text { distance }\end{array}$ & Compactness \\
\hline $\begin{array}{l}\text { Elementary } \\
\text { stage }\end{array}$ & 0.6601 & 1.3439 & $32.08 \%$ & 1.485 & 0.333 \\
\hline $\begin{array}{l}\text { Growing } \\
\text { stage }\end{array}$ & 1.2745 & 1.6967 & $44.12 \%$ & 1.434 & 0.696 \\
\hline Plateau stage & 1.5294 & 1.7566 & $43.68 \%$ & 1.451 & 0.775 \\
\hline
\end{tabular}

The TIN of Grace became more and more connected and compacted over the three stages of technological innovation.

The density of Grace's TIN increased significantly from the elementary stage to the growing stage and then increased slightly in the plateau stage (See Table 3). The performance of technological innovation in Grace became very significant in the growing stage compared to elementary stage (see Graph1). Then the performance reached another new peak and after that stopped growing in the plateau stage.

We attribute the prosperousness of technological innovation in the growing stage to significant and increased opportunity and frequency of interaction between people. 
This was confirmed by the interviews with the Grace President and managers. In 2000 Grace constructed a whole-people-participating internal technological innovator network. Employees from different functional department with different knowledge and skills were able and were encouraged to talk to each other and work with each other. The project teams -- a distinctively new structure whose members are from different departments was created. These project teams are very flexible in size and functions. The hybrid-matrix-like project teams can be flexibly involved in big and small scale of innovation projects. In the same year Grace implemented another important policy called inside-out-and-outside-in policy with which outside experts were invited to the company for technological supervising or training and inside employees were sent out to visit companies or study in the universities. These two measures To support and coordinate technological innovation projects, the Science and Technology Administration Department (S\&T) was set up in that year. The S\&T Department together with HR Department coordinated with different departments arranging personnel for technological innovation projects and these projects were given different priority according to the firm's business strategy. Team leaders of the projects with high priority had advantage to get particular people whom they wanted. As the S\&T manager remembered:

"At that time S\&T was a new department which was probably the first one in the chemical fiber industry in China. My job was to help people from both outside and inside, connect to each other and work with each other. The outcome was great. We not only had good performance in technological innovation but also trained our employees."

The further increase of density and decrease of network centralisation in the plateau stage, which means more dense and more widespread interaction between actors, go along with a further increase of technological innovation performance but the increase didn't last long.

We attribute the plateau phenomenon to the S-curve of group learning. In an intensively connected network, there are stable relationships and mutual trust among actors ${ }^{9}$. But when the intensive connections exist for a certain period of time, when everybody knows more and more about what the others know, the interaction or exchange will become less and less productive and innovative. This can also be explained by the S-curve of group learning (Gersick, 1991). The explanation has been justified by the Grace managers. The vice president of production commented:

"Even though the statistics of technological innovation performance are still good in 2006 and 2007, we have already felt a kind of innovation fatigue. People are not as enthusiastic as before. When it comes to developing inside potential of the employees, it becomes more and more difficult. When it comes to cooperating with outsiders, the number of cooperation is increasing but the effects are still

\footnotetext{
9 According to knowledge management theory, such stable relationship and mutual trust is significantly important for sharing common standard and routines which will further help for exchange of know-how and tacit knowledge among actors. Learning process is collective because it requires collaboration of different people with different capabilities and knowledge.
} 
doubtable”.

Based on such observation in Grace, we argue that the more frequent knowledge sharing and interactive learning results from a more connected and compacted network. In such network more number of people can cross shorter social distance to learn from each other. When the connectedness of an organisational structure increases, it may indicate an increase of the extent of resource-sharing and cooperation (Powell et al., 1996). More frequent interaction between people provides more opportunities for organisational learning in the network, consequently the performance of technological innovation improved. But it does not necessarily mean that higher is the density the better. When density increased to a certain level, the effectiveness of the network in terms of knowledge sharing and technological innovation may go down because of the S-curve of group learning.

\section{The TIN became bigger and more diversified over the three stages of technological innovation.}

The TIN of Grace got more actors involved since the growing stage. One more insider and four more outsiders joined in. Among the newcomers the S\&T Department (ST) is the only insider. It acts more like a knowledge broker than a knowledge resource for organisational learning in Grace. We observed that it has been in the core of the TIN after its establishment in 2000. Its degree, betweenness, and closeness have been in the highest group (See Table2).

The other four newcomers are all outsiders, namely industry associations (IA), consulting companies (CSL), legal services agencies (LAW), and private investors (INV), and competitors (CPT). The type of connection with these four outsiders is either for open information sharing which means accessing knowledge without the need to pay, or acquisition of goods, such as purchasing machine, patents, license, service, expertise, and so on. Although there was no active participation in joint innovation projects with these outsiders, the connections with them were still important for Grace to enrich their knowledge base and foster their organisational learning as these actors are of totally different background and specialty from Grace. But as the president of Grace commented:

"We learned something from our outside co-operators but far from enough. The effectiveness of learning depended on how much Grace could absorb and to what extent they could develop common goals and find common interest between Grace and its partners".

We argue that the diversity of actors provides an opportunity for diversity of knowledge sets for innovation. This is justified by the comments from the Grace managers that since the growing stage more outsiders contributed to Grace's technological innovation by knowledge sharing and transfer even though there were no joint technological innovation projects with most of them and the exception to this is the customers and suppliers. But the extent to which this opportunity is fully deployed will be a function of the role that these external actors play in the network, as we will discuss next. 
Most of the core members of the TIN in Grace are insiders and most of the outsiders are in the peripheral area over the three stages of technological innovation.

We conducted the core/peripheral analysis on the relational data over the three stages and got a result as shown in Table 4.

Table 4 Core/peripheral analysis of the TIN over three stages (actors with underlined names are outsiders)

\begin{tabular}{|c|c|c|c|}
\hline & Elementary stage & Growing stage & Plateau stage \\
\hline \multirow[t]{2}{*}{ Core actors } & PRD GOV HR PCH MKT & PRD MKT ST FIN RD & PRD RD ST MKT FIN \\
\hline & FIN RD LOG & HR & \\
\hline \multirow{3}{*}{$\begin{array}{l}\text { Peripheral } \\
\text { actors }\end{array}$} & $\underline{\text { SPL CST RI UNI }}$ & 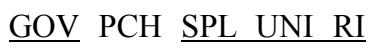 & HR GOV SPL PCH $\underline{\text { CST }}$ \\
\hline & & CST IA LOG CSL LAW & LOG INV IA CSL UNI RI \\
\hline & & CPT & CPT LAW \\
\hline
\end{tabular}

The results are consistent with our observation that in Grace the overwhelming majority of technological innovations was from within the company. Although there were several attempts in the past ten years, there was not even a single success in terms of joint R\&D program with social knowledge infrastructures such as universities and scientific research institutes. The outsiders played roles of information transferring and knowledge sharing rather than knowledge creation. The only two exceptions are customers and suppliers. But their participations were still limited in terms of scale and scope.

According to the interviews, there are two possible explanations to why the external actors of the TIN of Grace play a very limited role.

From the regional perspective, the interviewers attributed the formation of the insider-dominated TIN of Grace to the distinctive geographical environment of Grace. Grace nests in the Sichuan basin surrounded by mountains in Southwest China. Sichuan is far from the economic, political and cultural centers of China, and Yibin, the city of Grace, is even far from the center of Sichuan. Grace has to pay 500RMB per tonne more for transporting their products to the customers than their main competitors because of its disadvantaged geographic location. Sichuan province ranks 21 st among the 31 provinces in China in terms of GDP per capita in $2007 .^{10}$ This was the best performance in the past ten years. While China's dependence on foreign trade stands at $70 \%$, the corresponding figure for Sichuan is a mere $9 \% .11$ In China's economic landscape Sichuan is a relatively close area rather than an open economy. Sichuan has been a province which was considered to be geographically secluded, economically disadvantaged, and culturally self-enclosed. Things have been improved in the past decades but compared with other regions in China, especially the coastal

\footnotetext{
${ }^{10}$ Statistical Communique of the People's Republic of China on the 2006 National Economic and Social Development http://www.stats.gov.cn/tjgb/index.htm

11 Source: OECD Reviews of Innovation Policy OECD Reviews of Innovation Policy: China 2008
} 
regions, the progress is still too slow to create a fundamental change in its conditions. Therefore, it is relatively difficult for Grace to have a number of choices in accessing and forging strategic partnership with good consulting companies, legal service agencies, and private investors in Sichuan. It is also difficult to find some successful examples of strategic technological alliance in Sichuan to learn from. In other words, the technological distance between Grace and its local partner is high and therefore, the possibilities for the transfer of knowledge are limited.

From the industrial perspective, the interviewers attribute the feasibility of the insider-dominated TIN to the nature of the Chemical fiber industry. Chemical fiber industry in China is a traditional industry with mature production technology and is dominated by homogeneous products. On the one hand, the R\&D cycle is 12 to 24 months which means technology does not change very fast. This gives space and time for Grace to train its own people and develop new technology in-house. On the other hand, in China's chemical fiber industry, innovation is something more about process than product. The main purpose of process innovation is to improve the performance of existing products and to lower the cost. When it comes to process innovation, it is more a work of the people who work with the production process rather than a job for the researchers in the laboratory. In this sense, it is possible to have a productive innovator network which mainly consists of insiders. But a critical question is if that structure can be maintained when the focus is not on process innovation but on product innovation. A deeper look into the positioning of actors may provide some answers to this question. 


\subsection{The change of the positioning of actors in the TIN and its impact on technological innovation}

Table 5 presents the node properties of the TIN of Grace throughout the three periods.

Table 5: Node properties of the TIN of Grace in the three stages

\begin{tabular}{|c|c|c|c|c|c|c|c|c|c|c|c|c|}
\hline & \multicolumn{3}{|c|}{ Nrm Degree } & \multicolumn{3}{|c|}{ Nrm Bonacich Power } & \multicolumn{3}{|c|}{ Nrm Betweenness } & \multicolumn{3}{|c|}{ Nrm Closeness } \\
\hline & ELM & GRW & PLA & ELM & GRW & PLA & ELM & GRW & PLA & ELM & GRW & PLA \\
\hline MKT & 16.471 & 47.059 & 52.941 & 3.819 & 6.425 & 6.165 & 2.42 & 3.775 & 6.203 & 13.71 & 43.59 & 85 \\
\hline FIN & 25.882 & 45.882 & 44.706 & 6.001 & 6.264 & 5.206 & 0.795 & 10.195 & 6.323 & 13.821 & 48.571 & 85 \\
\hline $\mathrm{RD}$ & 18.824 & 44.706 & 65.882 & 4.365 & 6.104 & 7.672 & 1.445 & 8.732 & 11.813 & 13.821 & 48.571 & 100 \\
\hline PRD & 42.353 & 64.706 & 69.412 & 9.82 & 8.834 & 8.083 & 7.926 & 8.67 & 8.014 & 14.05 & 48.571 & 94.444 \\
\hline LOG & 14.118 & 11.765 & 17.647 & 3.273 & 1.606 & 2.055 & 0.808 & 0.315 & 0.672 & 13.6 & 39.535 & 68 \\
\hline $\mathrm{PCH}$ & 25.882 & 25.882 & 25.882 & 6.001 & 3.534 & 3.014 & 2.136 & 2.565 & 1.768 & 13.821 & 42.5 & 70.833 \\
\hline HR & 28.235 & 35.294 & 35.294 & 6.547 & 4.819 & 4.11 & 3.65 & 1.958 & 1.983 & 14.05 & 43.59 & 73.913 \\
\hline ST & 0 & 47.059 & 64.706 & 0 & 6.425 & 7.535 & 0 & 3.257 & 11.813 & & 44.737 & 100 \\
\hline RI & 7.059 & 14.118 & 12.941 & 1.637 & 1.927 & 1.507 & 0.699 & 0.604 & 0.174 & 13.6 & 41.463 & 60.714 \\
\hline UNI & 7.059 & 15.294 & 15.294 & 1.637 & 2.088 & 1.781 & 0 & 0.315 & 0.174 & 13.281 & 40.476 & 60.714 \\
\hline GOV & 30.588 & 35.294 & 29.412 & 7.093 & 4.819 & 3.425 & 3.65 & 2.252 & 0.082 & 14.05 & 43.59 & 62.963 \\
\hline IA & 0 & 12.941 & 16.471 & 0 & 1.767 & 1.918 & 0 & 0.092 & 0.082 & 0 & 36.957 & 58.621 \\
\hline CSL & 0 & 10.588 & 16.471 & 0 & 1.446 & 1.918 & 0 & 0 & 0.174 & 0 & 37.778 & 62.963 \\
\hline LAW & 0 & 9.412 & 7.059 & 0 & 1.285 & 0.822 & 0 & 0 & 0 & 0 & 36.957 & 54.839 \\
\hline INV & 0 & 0 & 17.647 & 0 & 0 & 2.055 & 0 & 0 & 0 & 0 & 0 & 58.621 \\
\hline SPL & 12.941 & 17.647 & 25.882 & 3.001 & 2.409 & 3.014 & 0 & 0.56 & 1.38 & 13.178 & 39.535 & 68 \\
\hline CST & 8.235 & 14.118 & 24.706 & 1.91 & 1.927 & 2.877 & 0 & 0 & 0 & 13.178 & 36.957 & 60.714 \\
\hline CPT & 0 & 7.059 & 8.235 & 0 & 0.964 & 0.959 & 0 & 0.092 & 0.082 & 0 & 38.636 & 60.714 \\
\hline
\end{tabular}

* ELM represents elementary stage, GRW represents growing stage, and PLA represents plateau stage 


\section{The change of the positioning of actors inside of the firm and its impact on technological innovation}

The node centrality is the most frequently used parameter to measure the power of the position of an actor in the network. First, we respectively discuss the change of the centrality of the four most centralized actors namely the production department (PRD), the R\&D department (RD), the science and technology administration department (ST), and the marketing department (MRK). Second, we discuss the overall change of the centrality of them as a whole.

The production department (PRD) has taken the most central position in the core of the TIN of Grace over the three stages, but its position slightly changed away from the very center in terms of betweenness and closeness from the elementary stage to the booming and then plateau stage. The degree and Bonacich power of PRD department has been the highest among all the actors over the three stages of Grace (see Table 4). But its highest position in betweenness and closeness at the time of the elementary stage and growing stage was overtaken by RD and ST in the plateau stage. That means over the three stages, PRD not only has had the biggest number of connections with the actors in the network but also has been connected to the largest number of powerful actors in the network. But it is no longer the actor who has the most opportunities to be a broker and no longer the one which is the closest to the others in the network at the time of plateau stage. PRD's central position is consistent with the core competence of low-cost-manufacturing based on technological innovation which we identified in our previous research and with a technology strategy based on process innovation that characterised the elementary and growth stages. $^{12}$

The marketing department (MKT) has been one of the core actors in the TINs over the three stages. Since the growing stage, the degree, betweenness, closeness and Bonacich power of MKT have ranked top three (see Table 4) despite that the increase of its centrality was not as good as those of RD and ST from growing stage to plateau stage. MKT has been an important knowledge broker between Grace and its customers. The information, such as what the customers need, what the benefit and problems they have when using the products of Grace, what the suggestions they have for Grace to improve the performance of their products, were collected and conveyed by the MKT. Grace's customers are mainly located in the east and south of China. MKT has the strongest connection with customers among all the other actors of the TIN.

The R\&D department (RD) and the S\&T department (ST) became more and more central over the three stages. The absolute number of degree, betweenness, Bonacich power, and closeness of RD and ST kept increasing throughout the three stages. The rank of the degree, betweenness, Bonacich power, and closeness of RD kept

12 See Liu et al's working paper for CICALICS Workshop 2006: "Building Technological-innovation-based Strategic Capabilities at Firm Level in China: a Case Study of a Textile Company" 
increasing over the three stages. The rank of the degree and Bonacich power of ST remained the same since it was established in the growing stage, while its rank of betweenness and closeness increased.

To summarize, first, we observed a continuous increase of degree, betweenness, and closeness centrality of almost all the inside actors over the three stage. The only obvious counter change happened to Financial Department (FIN). But according to our investigation the function of FIN in technological innovation is mainly collecting and sharing financial information. So the change of the centrality of FIN did not have significant influence on organisational learning for technological innovation in the TIN. Second, we found a change in the relative position of the four key actors. RD and ST took the central position in betweenness and closeness. They also had a significant increase in both degree and Bonacich power while the most centered PRD just had a slight increase in degree and even a decrease in Bonacich power.

It is interesting to see the delicate change of the relative position of ST and RD on the one side and that of PRD and MKT on the other side. By comparing Graph 1 and Graph 2, we found that when the centrality of PRD and MKT is higher than that of the $\mathrm{ST}$ and $\mathrm{RD}$, the performance of process innovation is mostly better than the product innovation. When the centrality of ST and RD is higher than the PRD and MKT, the performance of product innovation is mostly better than that of the process innovation. This is a very interesting finding.

When it comes to technological innovation activities, ST and RD work more with science while PRD and MKT work more with experience. Product innovation in Chemical fiber industry is more science based and the process innovation in the industry is more experience based. Savory (2006) distinguished between innovation led by formal R\&D efforts and more "practice-based" innovations which are the result of staff developing ideas and inventions in the course of their normal work and the result of an organic and emergent process. Practice-based innovation is likely that much "hybridisation" of technology occurs within a practice-based setting. The features of practice-based innovations include knowledge produced in the context of application, trans-disciplinary, and heterogeneity of sites in which knowledge is produced, social accountability and reflexivity (Nowotny et al., 2003). This distinction is echoed by the identification of STI and DUI mode. Jensen et al. (2007) identified two modes of learning for innovation, namely the STI mode and the DUI mode. The Science, Technology and Innovation (STI) mode is based on the production and use of codified scientific and technical knowledge, and the Doing, Using and Interacting (DUI) mode is an experienced-based mode of learning. We categorize the role of ST and RD to the STI or practice-based innovation mode, while the role of PRD and MKT to the DUI and practice-based innovation model.

We argue that in the TIN, the more central the actor is the more interactive learning the actor does and the better technological innovation performance related to this particular actor the TIN has. When the company adopts the process innovation based strategy, the PRD and MKT becomes the core actor. The learning occurs in the TIN is maily of the DUI mode. When the company adopts the production innovation 
based strategy, the RD and ST becomes the central player in the TIN. The learning occurs in the TIN shifts to the STI mode. The question is if a product innovation based strategy can be supported by an inward-looking TIN.

\section{The change of the positioning of actors outside the firm and its impact on technological innovation}

The centrality of the actors outside of Grace mainly kept increasing over the three stages. The only significant decrease in centrality happened to the government (GOV). Government is the only outside actor who was in the central area of the TIN and who continually has strong tie with the Grace's inside actors.

Government was the core actor in the elementary stage from 1997 to 1999. Since then government has been moving out of the center of the TIN. Its degree, betweenness and Bonacich power mainly decreased continually. It gives us an impression that in general the centrality of the government decreased over the three stages. But we should be careful when explaining the network dynamics only by degree centrality measures because they only take into account the immediate ties that an actor has, or the ties of the actor's neighbors, rather than indirect ties to all others. We see in Graph 3 that the closeness of government increased significantly throughout the three stages which means the government has shorter distance to the rest of the actors in the TIN. Closeness centrality approaches emphasize the distance of an actor to all others in the network by focusing on the distance from each actor to all others. Combining the analysis on both degree centrality and closeness centrality, we found that government has had less direct connections but more indirect connections since the growing stage. In other words, the government became less central in a local neighborhood but more connected from the network as a whole. The change in pattern of connection was justified by the comments of the Grace managers and a director of the Economy Committee of Yibin City. Since 2004 the local government decided to adjust its role from a supervisor to a supporter. Government tended not to directly interfere in the daily operation of the state-owned company but indirectly back them up, such as provide favorable policy and legal support. In this sense, government had less direct connection within the network but was closer to all the actors in the network. Grace considered that the support of the local government is one of the most important factors for its success.

Universities and research were truly sidelined in the TIN of Grace during the three stages in the past ten years. Centrality of universities was kept in the lowest group (see Table 3). Research institutes were also in a similar position. In Sichuan province where Grace is located, there is a research institute of textile industry, a textile school in Sichuan University, a textile college and many other universities. But the cooperation with research institutes was mainly limited to open information sharing and acquisition of goods, such as service, software and expertise, and so on during all three stages. Grace's cooperation with universities was also limited to recruiting university graduates in the elementary stage plus sharing technological information in the booming and plateau stage. Grace gave up cooperating with universities on R\&D after a failed attempt in 2002. In 2007, Grace began to have joint 
programmes with universities and research institutes but the scale and scope of the cooperation is still very limited and the company is still very cautious with such programmes.

Customers (CST) and suppliers (SPL) also have strong ties with Grace's inside actors. Even though these two actors have never been in the central area of the TIN of Grace, the exchange between Grace and CST and SPL is important to the technological innovation. The connection between Grace and its customers and suppliers included all three kinds of connection, namely open information sharing, goods acquiring, and innovation cooperation. The knowledge and information from these two actors are crucial to both the input and output of the TIN.

In summery, the low profile of external actors in the network was compatible with the process-based technological strategy that was dominant in the first years of the analysed period. This peripheral character of the external actors hasn't changed over time. While there are a larger variety of external actors in the network, they play only a marginal role.

Combining with the analysis about the positioning of inside actors afore, we argue that when Grace shifted from process innovation based strategy to product innovation based one, the learning mode shifted from DUI mode to STI mode. In the STI mode of learning, the external linkages with knowledge infrastructures are allimportant. In the case of Grace, when the firm's technological innovation strategy shifted, its TIN didn't change accordingly from introverted format to open structure. That is the reason for the technological innovation fatigue with which the performance of technological innovation stopped growing in the plateau stage.

\section{Concluding remarks}

In this paper we examined the dymanics of a technological innovator network of a stae-owned textile company in the underdeveloped southwest China to see how the structure of the TIN evolved in the past ten years and what impact it had on the technological performance of the firm.

The analysis shows that changes in the configuration of the TIN over time had an impact on not only the amount of technological innovations but also the predominant type (product versus process innovations) of technological innovations.

From a theoretical perspective, our findings confirm that the connectedness of the network is positively related to technological innovation performance, but the relation is not linear. More connected and compacted network results in more frequent interactive learning because more number of people can cross shorter social distance to learn from each other. When the connectedness reaches to a certain level, interactive learning will be less and less efficient thanks to the S-curve effect of group learning. Then the technological innovation performance of the TIN may stop growing or grow at a lower rate. Higher centrality of an actor is related to more interactive learning of this particular actor in the TIN. The more central the actor is 
the more interactive learning the actor experiences and the better technological innovation performance related to this particular actor the TIN has.

As the firm moved from a process oriented strategy towards a product oriented strategy, the TIN became more connected and compacted, and more diversified, but has always been inward looking with the external actors stayed at the peripheral area. The role that different actors play in the network also changed over time. The absolute predominance of the production department is substituted by a more prominent role of the R\&D department and the science and technology administration department in the later stages. These changes in the network structure are accompanied by an observed technological fatigue and, as we argue, can explain the technological fatigue.

A predominant inward looking TIN is consistent and can be adequate for a process-based technological strategy, particularly in the textile industry. Process innovation is likely to occur through learning by doing and, in the textile industry, this mainly occurs in the production department. The centrality of the production department is also coherent with this form of strategy. The result of the alignment between technological strategy and structure of the TIN is an extraordinary performance in process innovation.

However, our analysis shows that changes in the technological strategy need to be fitted with a transformation of the structure of the TIN. Although the managers of Grace have argued that the configuration of the TIN has always followed the technological strategy of Grace, our analysis shows that it has not been the case. The central role of the R\&D department and the S\&T Administration office suggest a move towards a more science-based and product based strategy. This type of strategy is founded in a substantially different mode of learning - STI mode of learning as opposed to learning by doing. In this mode of learning, the external linkages with knowledge providers are fundamental. But these external actors are only peripheral and play a very marginal role in the TIN of Grace which could explain the technological fatigue observed by the managers at Grace.

In sum, inward looking, production centered TINs are adequate for a process-focus technological strategy, but they are not enough for a product and science-based strategy that Grace wants to pursue. For that, the firm needs to develop stronger ties with external networks. 


\section{REFERENCES}

Asheim, B. and M. Gertler (2005). "The geography of innovation: regional innovation systems".in J. Fagerberg, D. Mowery and R. Nelson The Oxford Handbook of Innovation. Oxford, OUP, pp: 291-317.

Becattini, G. (1990). "The Marshallian industrial district as a socio-economic notion".in G. Becattini, Industrial Districts and Inter-Firm Co-Operation in Italy. Geneva, International Institute for Labor Statistics, pp: 37-51.

Bonacich, P., (1972), "Factoring and Weighting Approaches to Status Scores and Clique Identification”, Journal of Mathematical Sociology, 2, 113-120

Borgatti, S. P. (2005). Centrality and network flow. New Orleans, Elsevier.

Burt, R. S. (1992). Structural holes. Cambridge, Cambridge University Press.

Camagni, R., Ed. (1991). Innovation networks: spatial perspectives. London, Belhaven Press.

Carlsson, L.G. and A.C. Sandström (2008) "Network Governance of the commons", International Journal of the Commons, 2(1), pp: 33-54.

Cooke, P. (1996). "The new wave of regional innovation networks: analysis, characteristics and strategy." Small Business Economics 8, pp: 159-171.

Dantas, E. (2006). The development of knowledge networks in tlatecomer innovation systems: the case of Petrobras in teh Brazilian offshore oil industry. SPRU. Brighton, Sussex University. DPhil.

Das, T. K. and B. S. Teng (2002). "Alliance constellations: a social exchange perspective." Academy of Management Executive 27(3), pp: 445-456.

D'costa, A. P. (2002). "Export Growth and Path-Dependence The Locking-in of Innovations in the Software Industry." Science Technology \& Society 7(1), pp: 51-89.

D'costa, A. P. (2003). "Institutions and Industrial Governance in India: Learning to Cooperate the Japanese Way." Asian Business \& Management 2(1), pp: 63-89.

De Bresson, C. and F. Amesse (1991). "Networks of innovators : a review and introduction to the issue." Research Policy 20(5), pp: 363-379.

Ebadi, Y.M. and Utterback, J.M. (1984), "The Effect of Communication on Technological Innovation", Management Science, 30(5), 572-586

Edquist, C. (2005), "Systems of Innovaiotn: Perspectives and Challenges", in Fagerverg, J., Mowery, D.C. and Nelson, R. R. (ed.), The Oxford Handbook of Innovation, Oxford University Press, New York

Edquist, C. and Johnson, B. (1997), Institutions and Organisations in Systems of Innovation, in Edquist, C. (ed.) Systems of Innovation: Technologies, Institutions and Organizations, London and Washington: Pinter/Cassell Academic

Fagerberg, J. (2005), "Introduction: A Guide to the Literature", in Fagerberg, J., Mowery, D.C. and Nelson, R. R. (ed.), The Oxford Handbook of Innovation, Oxford University Press, New York

Freeman, L. C. (1979), “Centrality in Network: Conceptual clarification”, Social Networks, 1, 215-239

Freeman, C. (1991), "Networks of Innovators: a Synthesis of Research Issues", 
Research Policy, 20(5), 499-514.

Gereffi, G., Humphrey, J., Sturgeon, T. (2005). "The governance of global value chains." Review of International Political Economy 12(1), pp: 78-104.

Gersick, C. (1991), "Revolutionary Change Theories: A Multilevel Exploration of the Punctuated Equilibrium Paradigm", The Academy of Management Review, 16(1), 10-361

Gilsing, V., B. Nooteboom, et al. (2008). "Network embeddedness and the exploration of novel technologies: Technological distance, betweenness centrality and density." Research Policy 37(10), pp: 1717-1731.

Giuliani, E. and M. Bell (2005). "The micro-determinants of meso-level learning and innovation: evidence from a Chilean wine cluster." Research Policy 34(1), pp: 47-68.

Granovetter, M. S. (1973). "The strength of weak ties." American Journal of Sociology 78(6), pp: 1360.

Hagerdoorn, J. (1990). "Organisational modes of inter-firm cooperation and technology transfer." Technovation 10(1), pp: 17-30.

Hagedoorn, J. (1993). "Understanding the Rationale of Strategic Technology Partnering - Interorganizational Modes of Cooperation and Sectoral Differences." Strategic Management Journal 14(5), pp: 371-385.

Hanneman, Robert A. and Mark Riddle. (2005). Introduction to social network methods. Riverside, CA: University of California, Riverside (published in digital form at http://faculty.ucr.edu/ hanneman/ )

Herminia, I. (1993), "Network Centrality, Power, and Innovation Involvement: Determinants of Technical and Administrative Roles", Academy of Management Journal, 36(3), pp: 471-502

Johnson, B. (1992). "Institutional learning".in B.-Ä. Lundvall National systems of innovation. Towards a theory of innovation and interactive learning. Londres, Pinter, pp: 23-44.

Kastelle, T., J. Potts, et al. (2009). The evolution of Innovation systems. DRUID Summer Conference 2009. Copenhagen.

Jensen, M. B., Johnson, B., Lorenz, E. Lundvall, B. A., (2007), "Forms of knowledge and modes of innovation", Research Policy, 36(5), pp:680-693

Lam, A. (2005), "Organisational Innovation", in Fagerverg, J., Mowery, D.C. and Nelson, R. R. (ed.), The Oxford Handbook of Innovation, Oxford University Press, New York

Lundvall, B.-Å., (1988), "Innovation as an interactive process: From user-producer interaction to the National Innovation Systems", in Dosi, G., Freeman, C., Nelson, R.R., Silverberg, G. and Soete, L. (ed.), Technology and economic theory, Pinter Publishers, London.

Lundvall, B.-A. (1992). "User-producer relationships, national systems of innovation and internalization".in B.-Ä. Lundvall National systems of innovation. Towards a theory of innovation and interactive learning. London, Pinter, pp: 45-67. 
Lundvall, B.A. (2004), “The Economics of Knowledge and Learning”, in Christensen, J. L. and Lundvall, B.A. (ed.) Product Innovation, Interactive Learning and Economic Performance, Elsevier Ltd.

Lundvall, B. A., (2007), "National Innovations Systems: Analytical Concept and Development Tool”, Industry- and Innovation, 14(1), pp:95-119.

Malmberg, A. and D. Power (2005). "(How) Do (Firms in) Clusters Create Knowledge?" Industry and Innovation 12(4), pp: 409-431.

Malerba, F. (2005). "Sectoral systems: how and why innovation differes across sectors".in J. Fagerberg, D. Mowery and R. Nelson The Oxford Handbook of Innovation. Oxford, OUP, pp: 380-406.

Marshall, A. (1930). Principles of Economics. London, MacMillan.

McCarthy, B. (2008), "The Evolution and Transformation of Networks: A Study of Private Health Insurance in Ireland", Irish Journal of Management, 29(1), pp:87-113

Narula, R. (2002). "Innovation systems and 'inertia'in R\&D location: Norwegian firms and the role of systemic lock-in." Research Policy 31(5), pp: 795-816.

Nonaka, I. and Takeuchi, H. (1995), The Knowledge Creating Company, Oxford University Press, New York

Nooteboom, B. (2004). Inter-firm collaboration, learning and networks. An integrated approach. London and New York, Routledge.

Nowotny, H., Scott, P. and Gibbons, M. (2003), "'Mode 2' revisited: the new production of knowledge - Introduction", Minerva, 41, 3, 179-94.

Oecd (2002). OSLO Manual. The measurement of scientific and technological activities. Proposed guidelines for collecting and interpreting technological innovation data. Paris, OECD.

Pietrobelli, C. and R. Rabellotti (Forthcoming 2009). "Innovation Systems and Global Value Chains".in B.-A. Lundvall, K. Joseph, C. Chaminade and J. Vang handbook of Innovation Systems and Developing Countries. Chentelham, Edward Elgar.

Piori, M. and C. Sabel (1984). The second industrial divide. New York, Basic Books.

Porter, M. E. (1998). "Clusters and the new economics of competition." Harvard Business Review 76(6), pp: 77-90.

Powell, W.W., Koput, K.W. and Smith-Doerr, L. (1996), "Inter-organisational Collaboration and the Locus of Innovation: Networks of Learning in Biotechnology", Administrative Science Quarterly, 41, pp:116-145

Powell, W.W. and Grodal, S. (2005), "Networks of innovations" in Fagerverg, J., Mowery, D.C. and Nelson, R. R. (ed.), The Oxford Handbook of Innovation, Oxford University Press, New York

Robins, S. (2002), Organisational Behavior, Prentice Hall

Sabatier, P.A. and Jenkins-Smith, H.C., eds. (1993), Policy Change and Learning: An Advocacy Coalition Approach. Boulder, CO: Westview Press.

Savory, C. (2006), "Translating Knowledge to Build Technological Competence", Management Decision, 44, 8, 1052 - 1075

Saxenian, A.-L. (1994). Regional advantage: culture and ocmpetition in Silicon Valley 
and Route 128. Cambridge, Harvard University Press.

Scott, J. (2000), Social Network Analysis. A Handbook, London: Sage Publications

Soh, P. H. and E. B. Roberts (2003). "Networks of innovators: a longitudinal perspective." Research Policy 32(9), pp: 1569-1588.

Storper, M. (1997), The Regional World: Territorial Development in a Global Economy, New York and London: The Guilford Press.

Sturgeon, T., J. Van Biesebroeck, et al. (2008). "Value chains, networks and clusters: reframing the global automotive industry." Journal of Economic Geography 8(3), pp: 297-321.

Tsai, W. (2001). "Knowledge transfer in intra-organizational networks: effects of network position and absorptive capacity on business unit innovation and performance." Academy of Management Journal(44), pp: 996-1004.

Tsai, Y.C. (2006), "Effect of Social Capital and Absorptive Capability on Innovation in Internet Marketing”, International Journal of Management, 23(1), 157-167

Wasserman, S. and Faust, K. (1994), Social Network Analysis: Methods and Applications. New York: Cambridge University Press. 


\section{CIRCLE ELECTRONIC WORKING PAPERS SERIES (EWP)}

CIRCLE (Centre for Innovation, Research and Competence in the Learning Economy) is a multidisciplinary research centre set off by several faculties at Lund University and Blekinge Institute of Technology. CIRCLE has a mandate to conduct multidisciplinary research and education on the following issues: Long-term perspectives on innovation, structural change and economic growth, Entrepreneurship and venture capital formation with a special focus on new ventures, The dynamics of R\&D systems and technological systems, including their impact on entrepreneurship and growth, Regional innovation systems in different national and international contexts, International comparative analyses of national innovation systems and Policy design based on policy learning,

The CIRCLE Electronic Working Paper Series are intended to be an instrument for early dissemination of the research undertaken by CIRCLE researchers, associates and visiting scholars and stimulate discussion and critical comment.

The working papers present research results that in whole or in part are suitable for submission to a refereed journal or to the editor of a book or have already been submitted and/or accepted for publication.

CIRCLE EWPs are available on-line at: http://www.circle.lu.se/publications

Available papers:

2009

WP 2009/01

Building systems of innovation in less developed countries: The role of intermediate organizations.

Szogs, Astrid; Cummings, Andrew and Chaminade, Cristina

WP 2009/02

The Widening and Deepening of Innovation Policy: What Conditions Provide for Effective Governance?

Borrás, Susana

WP 2009/03

Managerial learning and development in small firms: implications based on observations of managerial work

Gabrielsson, Jonas and Tell, Joakim

WP 2009/04

University professors and research commercialization: An empirical test of the "knowledge corridor" thesis

Gabrielsson, Jonas, Politis, Diamanto and Tell, Joakim

WP 2009/05

On the concept of global innovation networks

Chaminade, Cristina

WP 2009/06

Technological Waves and Economic Growth - Sweden in an International Perspective 1850-2005

Schön, Lennart 
WP 2009/07

Public Procurement of Innovation Diffusion: Exploring the Role of Institutions and Institutional Coordination

Rolfstam, Max; Phillips, Wendy and Bakker, Elmer

WP 2009/08

Local niche experimentation in energy transitions: a theoretical and empirical exploration of proximity advantages and disadvantages

Lars Coenen, Rob Raven, Geert Verbong

WP 2009/9

Product Development Decisions: An empirical approach to Krishnan and Ulrich Jon Mikel Zabala, Tina Hannemann

WP 2009/10

Dynamics of a Technological Innovator Network and its impact on technological performance

Ju Liu, Cristina Chaminade

2008

WP 2008/01

R\&D and financial systems: the determinants of R\&D expenditures in the Swedish pharmaceutical industry

Malmberg, Claes

WP 2008/02

The Development of a New Swedish Innovation Policy. A Historical Institutional Approach

Persson, Bo

WP 2008/03

The Effects of R\&D on Regional Invention and Innovation

Olof Ejermo and Urban Gråsjö

WP 2008/04

Clusters in Time and Space: Understanding the Growth and Transformation of Life Science in Scania

Moodysson, Jerker; Nilsson, Magnus; Svensson Henning, Martin

WP 2008/05

Building absorptive capacity in less developed countries

The case of Tanzania

Szogs, Astrid; Chaminade, Cristina and Azatyan, Ruzana

WP 2008/06

Design of Innovation Policy through Diagnostic Analysis:

Identification of Systemic Problems (or Failures)

Edquist, Charles

WP 2008/07

The Swedish Paradox arises in Fast-Growing Sectors

Ejermo, Olof; Kander, Astrid and Svensson Henning, Martin 
WP 2008/08

Policy Reforms, New University-Industry Links and Implications for Regional Development in Japan

Kitagawa, Fumi

WP 2008/09

The Challenges of Globalisation: Strategic Choices for Innovation Policy

Borrás, Susana; Chaminade, Cristina and Edquist, Charles

WP 2008/10

Comparing national systems of innovation in Asia and Europe: theory and comparative framework

Edquist, Charles and Hommen, Leif

WP 2008/11

Putting Constructed Regional Advantage into Swedish Practice? The case of the VINNVÄXT initiative 'Food Innovation at Interfaces'

Coenen, Lars; Moodysson, Jerker

WP 2008/12

Energy transitions in Europe: 1600-2000

Kander, Astrid; Malanima, Paolo and Warde, Paul

WP 2008/13

RIS and Developing Countries: Linking firm technological capabilities to regional systems of innovation

Padilla, Ramon; Vang, Jan and Chaminade, Cristina

WP 2008/14

The paradox of high R\&D input and low innovation output: Sweden

Bitarre, Pierre; Edquist, Charles; Hommen, Leif and Ricke, Annika

WP 2008/15

Two Sides of the Same Coin? Local and Global Knowledge Flows in Medicon Valley

Moodysson, Jerker; Coenen, Lars and Asheim, Bjørn

WP 2008/16

Electrification and energy productivity

Enflo, Kerstin; Kander, Astrid and Schön, Lennart

WP 2008/17

Concluding Chapter: Globalisation and Innovation Policy

Hommen, Leif and Edquist, Charles

WP 2008/18

Regional innovation systems and the global location of innovation activities: Lessons from China

Yun-Chung, Chen; Vang, Jan and Chaminade, Cristina 
WP 2008/19

The Role of mediator organisations in the making of innovation systems in least developed countries. Evidence from Tanzania

Szogs, Astrid

WP 2008/20

Globalisation of Knowledge Production and Regional Innovation Policy:

Supporting Specialized Hubs in the Bangalore Software Industry

Chaminade, Cristina and Vang, Jan

WP 2008/21

Upgrading in Asian clusters: Rethinking the importance of interactive-learning

Chaminade, Cristina and Vang, Jan

2007

WP 2007/01

Path-following or Leapfrogging in Catching-up: the Case of Chinese Telecommunication Equipment Industry

Liu, Xielin

WP 2007/02

The effects of institutional change on innovation and productivity growth in the Swedish pharmaceutical industry

Malmberg, Claes

WP 2007/03

Global-local linkages, Spillovers and Cultural Clusters: Theoretical and Empirical insights from an exploratory study of Toronto's Film Cluster

Vang, Jan; Chaminade, Cristina

WP 2007/04

Learning from the Bangalore Experience: The Role of Universities in an Emerging Regional Innovation System

Vang, Jan; Chaminade, Cristina.; Coenen, Lars.

WP 2007/05

Industrial dynamics and innovative pressure on energy -Sweden with European and Global outlooks

Schön, Lennart; Kander, Astrid.

WP 2007/06

In defence of electricity as a general purpose technology

Kander, Astrid; Enflo, Kerstin; Schön, Lennart

WP 2007/07

Swedish business research productivity - improvements against international trends

Ejermo, Olof; Kander, Astrid

WP 2007/08

Regional innovation measured by patent data - does quality matter?

Ejermo, Olof 
WP 2007/09

Innovation System Policies in Less Successful Developing countries: The case of Thailand

Intarakumnerd, Patarapong; Chaminade, Cristina

2006

WP 2006/01

The Swedish Paradox

Ejermo, Olof; Kander, Astrid

WP 2006/02

Building RIS in Developing Countries: Policy Lessons from Bangalore, India

Vang, Jan; Chaminade, Cristina

WP 2006/03

Innovation Policy for Asian SMEs: Exploring cluster differences

Chaminade, Cristina; Vang, Jan.

WP 2006/04

Rationales for public intervention from a system of innovation approach: the case of VINNOVA.

Chaminade, Cristina; Edquist, Charles

WP 2006/05

Technology and Trade: an analysis of technology specialization and export flows

Andersson, Martin; Ejermo, Olof

WP 2006/06

A Knowledge-based Categorization of Research-based Spin-off Creation

Gabrielsson, Jonas; Landström, Hans; Brunsnes, E. Thomas

WP 2006/07

Board control and corporate innovation: an empirical study of small technology-based firms

Gabrielsson, Jonas; Politis, Diamanto

WP 2006/08

On and Off the Beaten Path:

Transferring Knowledge through Formal and Informal Networks

Rick Aalbers; Otto Koppius; Wilfred Dolfsma

WP 2006/09

Trends in R\&D, innovation and productivity in Sweden 1985-2002

Ejermo, Olof; Kander, Astrid

WP 2006/10

Development Blocks and the Second Industrial Revolution, Sweden 1900-1974

Enflo, Kerstin; Kander, Astrid; Schön, Lennart 
The uneven and selective nature of cluster knowledge networks: evidence from the wine industry

Giuliani, Elisa

WP 2006/12

Informal investors and value added: The contribution of investors' experientially acquired resources in the entrepreneurial process

Politis, Diamanto; Gabrielsson, Jonas

WP 2006/13

Informal investors and value added: What do we know and where do we go?

Politis, Diamanto; Gabrielsson, Jonas

WP 2006/14

Inventive and innovative activity over time and geographical space: the case of Sweden

Ejermo, Olof

2005

WP 2005/1

Constructing Regional Advantage at the Northern Edge

Coenen, Lars; Asheim, Bjørn

WP 2005/02

From Theory to Practice: The Use of the Systems of Innovation Approach for Innovation Policy

Chaminade, Cristina; Edquist, Charles

WP 2005/03

The Role of Regional Innovation Systems in a Globalising Economy: Comparing Knowledge Bases and Institutional Frameworks in Nordic Clusters

Asheim, Bjørn; Coenen, Lars

WP 2005/04

How does Accessibility to Knowledge Sources Affect the Innovativeness of Corporations? Evidence from Sweden

Andersson, Martin; Ejermo, Olof

WP 2005/05

Contextualizing Regional Innovation Systems in a Globalizing Learning Economy: On Knowledge Bases and Institutional Frameworks

Asheim, Bjørn; Coenen, Lars

WP 2005/06

Innovation Policies for Asian SMEs: An Innovation Systems Perspective Chaminade, Cristina; Vang, Jan

WP 2005/07

Re-norming the Science-Society Relation

Jacob, Merle

WP 2005/08 
Corporate innovation and competitive environment

Huse, Morten; Neubaum, Donald O.; Gabrielsson, J onas

WP 2005/09

Knowledge and accountability: Outside directors' contribution in the corporate value chain

Huse, Morten, Gabrielsson, Jonas; Minichilli, Alessandro

WP 2005/10

Rethinking the Spatial Organization of Creative Industries

Vang, Jan

WP 2005/11

Interregional Inventor Networks as Studied by Patent Co-inventorships

Ejermo, Olof; Karlsson, Charlie

WP 2005/12

Knowledge Bases and Spatial Patterns of Collaboration: Comparing the Pharma and Agro-Food Bioregions Scania and Saskatoon

Coenen, Lars; Moodysson, Jerker; Ryan, Camille; Asheim, Bjørn; Phillips, Peter

WP 2005/13

Regional Innovation System Policy: a Knowledge-based Approach

Asheim, Bjørn; Coenen, Lars; Moodysson, Jerker; Vang, Jan

WP 2005/14

Face-to-Face, Buzz and Knowledge Bases: Socio-spatial implications for learning and innovation policy

Asheim, Bjørn; Coenen, Lars, Vang, Jan

WP 2005/15

The Creative Class and Regional Growth: Towards a Knowledge Based Approach

Kalsø Hansen, Høgni; Vang, Jan; Bjørn T. Asheim

WP 2005/16

Emergence and Growth of Mjärdevi Science Park in Linköping, Sweden

Hommen, Leif; Doloreux, David; Larsson, Emma

WP 2005/17

Trademark Statistics as Innovation Indicators? - A Micro Study

Malmberg, Claes 